\title{
The Pentagonal E-Portfolio Model for Selecting, Adopting, Building, and Implementing an E-Portfolio
}

\author{
Nicole Buzzetto-More and Ayodele Alade \\ University of Maryland Eastern Shore, \\ Princess Anne, MD, USA
}

\section{nabuzzetto-more@umes.edu; ajalade@umes.edu \\ Executive Summary}

Electronic portfolios are a student-centered outcomes-based assessment regime involving learners in the gathering, selection, and organization of artifacts synthesized into a compilation purposed to demonstrate knowledge, skills, and/or achievements supported by reflections that articulate the relevance, credibility, and meaning of the artifacts being presented. Electronic portfolios have been found to be a valid way to document student progress, encourage student involvement in assessment, showcase student work samples, promote students professionally, and provide a method of student learning outcomes and curriculum evaluation. However, electronic portfolio adoption represents a sizable commitment that is influenced by a number of variables and that requires foresight as well as a thoughtful strategy.

This paper presents a model for selecting, designing, and implementing an electronic portfolio project and illustrates its application through the presentation of a detailed case study of a successfully implemented and ongoing electronic portfolio project used as a comprehensive assessment measure to determine degree mastery in the Department of Business, Management, and Accounting at the University of Maryland Eastern Shore.

The model introduced in this paper is known as the Pentagonal E-Portfolio Model, named such for its five levels: 1) Level 1 - Identification of Needs; 2) Level 2 - Determination, Assessment, \& Budgeting; 3) Level 3 - System Selection and Strategic Planning; 4) Level 4 - Development; and 5) Level 5 - Implementation and Continuation.

Keywords: Electronic Portfolios, Electronic portfolios, Assessment, Student Learning Outcomes

\section{Introduction}

With the proliferation of technology across the educational spectrum, there has been increased interest in student portfolios. A student portfolio is an organized compilation of artifacts that demonstrates learning and achievement and includes exegesis that articulates relevance and meaning (Cooper \& Love, 2002). Over

Material published as part of this publication, either on-line or in print, is copyrighted by the Informing Science Institute. Permission to make digital or paper copy of part or all of these works for personal or classroom use is granted without fee provided that the copies are not made or distributed for profit or commercial advantage AND that copies 1) bear this notice in full and 2) give the full citation on the first page. It is permissible to abstract these works so long as credit is given. To copy in all other cases or to republish or to post on a server or to redistribute to lists requires specific permission and payment of a fee. Contact Publisher@InformingScience.org to request redistribution permission. the years, the focus has changed from what things people have been taught to how and what people have learned as well as the meaning behind the learning (Love \& Cooper, 2007).

Increasingly, student portfolios are being created using computer and Webbased technologies. Known as electronic portfolios, they have been described as the biggest innovation in educational 
technology since the introduction of course management systems, having tremendous potential across disciplines, institutions, and technological applications (Lorenzo \& Ittelson, 2005a).

Electronic Portfolios may be developmental, demonstrating individual progress overtime and serving as a form of value added assessment; reflective so as to include personal reflection on the content, what it means, and how it demonstrates learning mastery so as to encourage critical thinking and metacognition; or professional/representational where they showcase an individual's achievements. Frequently, multiple portfolio types exist and/or the types are blended into a hybrid format.

This paper is organized as follows: literature review, presentation of a 5-level model for portfolio development, implementation of the model in a successful e-portfolio project used in a higher education business program in the United States, and summary and future work.

\section{Literature Review}

Electronic portfolio adoption continues to grow exponentially according to campus surveys (Batson, 2005). Jafari (2004) explains that this is because academic leaders are excited by the prospects presented through electronic portfolios as they offer a contemporary and authentic way for students to demonstrate learning and the understanding of that learning in accordance with established objectives.

The ePortConsortium (2003) advocates the adoption of electronic portfolios at all educational levels, explaining that student portfolios not only encourage meta-cognition, but also help students develop organizational skills; recognize skills, abilities, and shortcomings; showcase talents; assess academic progress; demonstrate how skills have developed longitudinally; make professional decisions; demonstrate that one has met learning requirements; and promote themselves professionally. As a result, they assert that student learning portfolios are the most comprehensive and reflective means of expressing a broad range of student's accomplishments.

The pedagogic benefits of electronic portfolios have been identified as:

- Authentic learning, where learning is more meaningful when it is linked to real world experiences,

- Experiential learning, where students 'learn by doing' rather than learn through telling,

- Competency-based education, where instruction is outcomes based using electronic portfolios as part of student learning outcomes based performance assessment where assessment may include higher order skills,

- Lifelong learning, where learning is directed by the individual and guided by the individual's interests,

- Autodidactism, where learning is self-taught and self motivated, and

- Self-directed learning, where students take responsibility for their own learning (Love \& Cooper, 2007).

Chun (2002) said that a portfolio should require students to collect, assemble, and reflect on samples that represent the satisfaction of learning objectives, explaining that the portfolio building process encourages students to engage in structured reflection while they explore how learning translates into productive practice.

A number of significant oversight bodies advocate the usage of student learning portfolios. The Office of Educational Research and Improvement (1993a) recommends that performance assessments be used to augment or replace norm-referenced tests at all educational levels and included 
the use of portfolios as an effective means of quality performance assessment. Additionally, according to the American Association of Higher Education (2001), student learning portfolios are an excellent methodology around which can be anchored a successful outcomes-based assessment program.

While a number of papers have focused on the student processes involved in portfolio creation, resulting in a number of usable models, far fewer papers have focused on the electronic portfolio decision-making process at the institutional, program, and/or instructor level. An exhaustive review of the available literature has unearthed a handful of electronic portfolio decision making guides and/or models purposed to assist the academic community. Table 1 presents a summary of some of this information.

Table 1: Summary of Published Guidelines for E-Portfolio Decision Making

\begin{tabular}{|l|l|}
\hline AUTHORS & GUIDELINES \\
\hline Cooper (1999) & $\begin{array}{l}\text { Requisite considerations at the institutional level that should be modeled } \\
\text { when creating a student portfolio assessment project. } \\
\text { - Identification of skill areas } \\
\text { - Design of measurable outcomes } \\
\text { - Identification of learning strategies } \\
\text { - Identification of performance indicators } \\
\text { - Collection of evidence } \\
\text { - Assessment }\end{array}$ \\
\hline $\begin{array}{l}\text { Lorenzo \& Ittleson } \\
\text { (2005b) }\end{array}$ & $\begin{array}{l}\text { Guiding questions that need to be considered by any institution consider- } \\
\text { ing electronic portfolio adoption. } \\
\text { - Should an e-portfolio be an official record of a student's work? } \\
\text { - How long should an e-portfolio remain at an institution after the student } \\
\text { graduates? } \\
\text { - Who owns the e-portfolio? } \\
\text { - How should an institution promote and support the use of electronic } \\
\text { portfolios? } \\
\text { - How are electronic portfolios evaluated in a manner that is both valid } \\
\text { and reliable? }\end{array}$ \\
\hline - How can institutions encourage reflection in the design and use of elec- \\
tronic portfolios?
\end{tabular}




\begin{tabular}{|l|l|}
\hline Jafari (2004) & $\begin{array}{l}\text { Considerations that should guide the electronic portfolio adoption and } \\
\text { creation process } \\
\text { - The system's future users, } \\
\text { - Potential benefits, } \\
\text { - Technological features, } \\
\text { - Usability, and } \\
\text { Versatility. }\end{array}$ \\
\hline Butler (2006) & $\begin{array}{l}\text { Common issues related to portfolio implementation and maintenance } \\
\text { whose consideration must be a part of the decision implementation and } \\
\text { sustaining processes } \\
\text { - Lack of guidelines } \\
\text { - Overabundance of guidelines causing restriction } \\
\text { - Lack of examples from previous portfolios } \\
\text { - Lack of guidance } \\
\text { - Lack of support } \\
\text { - Interoperability } \\
\text { - Technical problems, } \\
\text { - Maintenance } \\
\text { - Lack of technology skills of students and staff, } \\
\text { - Lack of time } \\
\text { - Poor buy in, } \\
\text { - Accessibility } \\
\text { - Lack of security } \\
\text { - Student inexperience with authoring reflections, } \\
\text { - Unclear assessment strategies } \\
\text { - Lack of or too much feedback. }\end{array}$ \\
\hline \hline
\end{tabular}

Adoption and design should be influenced more by educational goals than technical issues (Cooper \& Love, 2002). To assist students, e-portfolio systems should include a full suite of software, templates, a means for students to bring in materials built elsewhere, and reflective student commentaries that serve as meta-documentation (Cooper \& Love, 2002).

Attributes for a successfully implemented portfolio have been identified as:

$\checkmark$ An understanding of both the process and the product of portfolio construction;

$\checkmark$ Clear framework and guidelines;

$\checkmark$ A balance of structure and freedom for creativity;

$\checkmark \quad$ Frequent and meaningful feedback;

$\checkmark$ A value of reflection;

$\checkmark$ Understanding of the value of the portfolio for future student professional usage;

$\checkmark$ Motivated students;

$\checkmark$ Student portfolio ownership; 
$\checkmark$ Portfolios that reflect students' outside lives;

$\checkmark$ Consideration of the target audience; and

$\checkmark$ Sensibility and organization (Butler, 2006).

The aforementioned guiding questions, considerations, requisite attributes, and models offer valuable contributions to the discourse on electronic portfolios. Undoubtedly, they have individually, and perhaps collectively, assisted a number of institutions in their e-portfolio decision making and adoption processes. Their usefulness is not being questioned, but still a comprehensive model is still missing from the larger literature. As a result, this paper offers an all-inclusive model whose usefulness is demonstrated through practical implementation in the form of a senior capstone electronic portfolio implemented within a business department at a mid-sized university located in the United States on Maryland's Eastern Shore.

\section{The Pentagonal E-Portfolio Adoption Model}

An electronic portfolio represents a sizable commitment, one that requires foresight as well as a thoughtful strategy. The model presented in Figure 1 and described in the following section is purposed to assist administrators in the portfolio decision making and adoption processes. It was influenced by the work of Cooper (1999), Jafari (2004), Butler (2006), Cooper and Love (2002), Lorenzo and Ittleson (2005b), and Zeichner \& Wray (2001). Known as the Pentagonal EPortfolio Model (see Figure 1) it was named such for its five levels. Embedded within the five levels are sixteen critical activities.

Following the presentation and elaboration of the Pentagonal E-Portfolio Adoption Model is a section which illustrates the practical real-world application of the model as it was utilized to guide the electronic portfolio decision, selection, development, testing, implementation, evaluation, and improvement process of a comprehensive electronic portfolio designed and implemented to measure degree mastery in an undergraduate business degree program. 


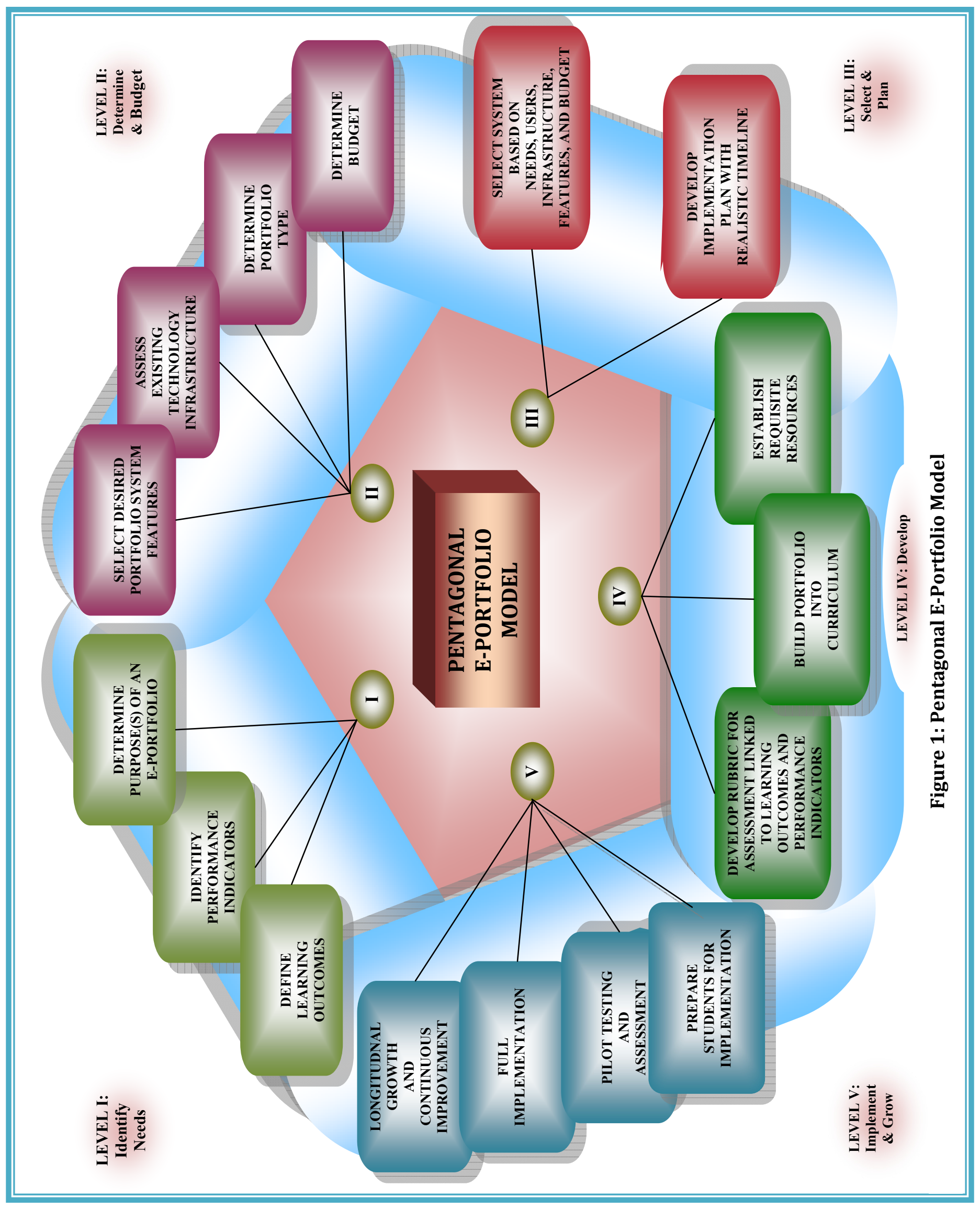




\section{Level I: Identification of Need}

The first level in the adoption process is the development of performance based student learning outcomes, the identification of measurable performance indicators, and the determination of the purpose(s) for the portfolio.

\section{Define Learning Outcomes}

Learning outcomes refer to the goals and objectives of the learning process (Martell \& Calderon, 2005 ) and are considered to be the bedrock of any successful assessment program (BuzzettoMore \& Alade, 2006). To ensure that the learning outcomes are being addressed within a program or curriculum, it is recommended that institutions engage in mapping where they directly link the outcomes to where in the program or curriculum they are being built.

\section{Identify Performance Indicators}

Performance indicators are the demonstrable performance based actions that can be measured (Walvoord \& Anderson, 1998). These must be communicated to students in advance of beginning an assessable activity and are usually articulated using the language represented in Bloom's Taxonomy of Educational Objectives which provides a recognized set of hierarchical behaviors that can be measured concurrent with student learning outcomes assessment (Harich, Fraser, \& Norby, 2005).

\section{Determination of Purpose(s)}

This occurs when it is decided whether the portfolio will be a form of value added assessment that demonstrates student growth overtime, be used as a culminating or capstone assessment measure that indicates mastery, be used as a means of professional promotion for the students, be utilized for course based assignments, or serve to satisfy multiple needs in a hybrid combination form. As suggested by Zeichner and Wray (2001), it is also important to decide who will control authorship and how much and how many guidelines should exist; how and what will the portfolios be organized around; what kinds of artifacts will most likely be acceptable; what, if any, standards and guidelines will be put into place; and how much input and guidance will be coming come from educators.

\section{Level II: Determination, Assessment, \& Budgeting}

The second level of the portfolio adoption model involves selecting the features desired in the portfolio system to be adopted, assessing the current technology structure that will support portfolio adoption, determining the type of portfolio to be adopted, and budgeting.

\section{Selection of Features}

There are a variety of features that can commonly be found in electronic portfolio systems. When selecting an electronic portfolio system for adoption it is important to understand the possible features as well as to have previously determined which are necessary to fit the long and short term needs of a particular institution. The selection of features was addressed by Sweat-Guy and Buzzetto-More (2007) who identified, as well as compared, the pros, cons, and practical implications of a number of common platforms. They explained that the following as features should be considered when selecting an electronic portfolio system for adoption or creation as well as discussed the benefits and drawbacks of the various options which included: 
- Student Advisement Capabilities;

- Artifact Types Supported;

- Assessment Regimes Supported, such as rubrics, exams, and/or surveys and whether they are supported, created, and or aggregated;

- Communication and Collaboration Capabilities;

- Course Management: Whether the e-portfolio needs to compliment, link to, or serve as a course management system;

- Format: Developmental, Demonstrate Mastery or Professional;

- Hosting and Storing Requirements;

- Intended User and User Type;

- Learning Outcome Creation and Artifact Linkage;

- Reflections: Supported/Unsupported and Types/Formats Enabled;

- Reporting Capabilities;

- Sharing: Who can be invited to view and/or assess portfolios; and

- Technological Considerations.

\section{Assessment of Current Technology Infrastructure}

Assessing the current technology infrastructure is important because it identifies any constraints that may exist and that require consideration during the decision making process. The technology audit to be conducted involves:

- Identifying server availability,

- Identifying availability of technical and administrative support,

- Conducting an audit of existing technology architecture,

- Analysis of existing course management system and whether there are portfolio products in compliment of that system,

- Possible relationships between e-portfolio deployments and campus enterprise systems, and

- Consideration of how an electronic portfolio system will be integrated within the existing infrastructure.

\section{Determine Portfolio Type}

When determining the type of portfolio to be purchased, adapted, or developed, the institution must question the very nature of their electronic portfolio and decide whether it should be an individualized self-assessment tool that is not constrained by student learning outcomes or, rather, a powerful piece of the assessment equation that links artifacts and reflections to learning goals and objectives (Lorenzo \& Ittelson 2005a). Lorenzo and Ittelson (2005a) have identified four types of electronic portfolios and Sweat-Guy and Buzzetto-More (2007) explained the pros and cons of each option.

- A homegrown portfolio is one that is created by an institution and is customized to meet unique institutional needs; however, the creation process can be expensive, time consuming, and burdensome. 
- An open source portfolio is one that is made publicly available at no charge and the source code is available for customization. Open source portfolios are risky as the institution incurs costs that may come from the need to customize, support, or upgrade. Since it is not a published product upgrades come from the user community and may or may not be timely. Furthermore, the community of institutions which use and upgrade the system may disband if, and when, the system falls out of favor.

- Commercial portfolios are available for purchase from vendors, are well developed, and include technical support; however, they can be costly to purchase and the support service may be poor or expensive.

- Common software created using software such as Front Page, MS Word, MS Publisher, and/or PowerPoint to support the creation of electronic portfolios. These are inexpensive; however, they are the most difficult for students to create and may be simple in structure.

\section{Determine Budget}

During the budgeting process, it is important to take into account the features that have been previously identified as being desirable, the purpose for the portfolio, and the type of portfolio that has been selected. Since there are many pricing possibilities, this is an important consideration. If an institution has a particularly limited or fixed budget that will not accommodate their previously determined features and type, then they will need to reassess and adjust accordingly. Additionally, the budget must take into account the cost of the system to be either purchased, adopted, or developed; the cost for customization (if needed) and installation (if applicable); the cost for continuous support (if applicable); planning for upgrades (if applicable); the cost for technology required to host the system (if applicable); the cost to students (if any); and the cost for the purchase and or development of resources.

\section{Level III: System Selection \& Strategic Planning}

The third level of the portfolio adoption model being presented involves system selection and the development of an implementation plan with a realistic timeline. This is an area that is often overlooked and/or rushed; however, it is crucial, with ramifications that will set the stage for the emerging portfolio project.

\section{System Selection}

When selecting the system it is important to take into account the features required, the type of portfolio identified as being desired, and the budget that has been developed. If purchasing a commercial product or adopting an open source platform, it is important to utilize the information gained to better inform the decision-making process so as to select the optimal portfolio to meet institutional needs. If the decision has been made to create a home grown portfolio, it is advisable to examine successful models that have been created. If an open source system has been selected, then this is the time to determine what modifications and accommodations will need to be made.

\section{Development of Strategic Implementation Plan}

Once a system has been selected, then it is crucial to develop a realistic and detailed implementation plan that includes a feasible timeline. The implementation plan must have several elements, which are illustrated in Table 2. 
Table 2: Elements of a 9 Step Strategic Implementation Plan

\begin{tabular}{l|l|}
\hline 1 & Installation and technological support \\
\hline 2 & Training \\
\hline 3 & Pilot testing \\
\hline 4 & $\begin{array}{l}\text { Development of assessment regime for assessing student } \\
\text { portfolios }\end{array}$ \\
\hline 5 & Resources that will need to be developed \\
\hline 6 & Evaluation or the adopted and pilot tested portfolio \\
\hline 7 & Improvement Prior to Full Implementation \\
\hline 8 & Full Implementation \\
\hline 9 & Long-Term Growth and Continuous Improvement \\
\cline { 2 - 2 }
\end{tabular}

\section{Level IV: Development}

The fourth level of the adoption process involves the establishment of resources, building the portfolio into the academic curriculum, and creation of the rubric and means that will be used to evaluate student portfolios.

\section{Establishment of Resources}

It would be highly unlikely that supplemental resources will not be needed in order for a successful implementation. These resources may be available for purchase or may require development. They include the purchasing of equipment for faculty and/or student usage, the development of training/ instructional manuals, the creation of sample portfolios, the establishment of a lab or workspace, etcetera.

\section{Build Portfolio into Curriculum}

When the portfolio is being built into the academic curriculum, the institution will need to determine whether it is being embedded into a capstone or other course; whether it is a stand alone activity or part of another experience such as an internship; whether a faculty member will help guide the portfolio process; when during their academic career the students will have access to the portfolio and how it will be introduced; and how, when, and by whom the portfolio will be evaluated. Course embedded portfolios are often the easiest to implement; however, the duration of the course usually poses a time constraint. When a portfolio is a form of value added assessment it may be incorporated into a series of courses or be a stand alone annual activity conducted by the larger program or department. For some institutions, portfolios are a means to exhibit and assess professional growth and competence linked to an internship. This methodology is particularly common in teacher education and nursing programs.

Furthermore, a portfolio may be guided by an instructor, an independent portfolio coordinator, or be completely left to the student. Increased guidance usually results in higher quality portfolios; however, to some extent, student creativity may be suppressed.

Additionally, when students should be first introduced to, as well as begin creating, their portfolio is a concern. Some feel that portfolio creation should be a longitudinal process whereas others advocating that portfolio creation should occur after students have reached a designated benchmark. 


\section{Rubric Development}

Evaluation is crucial and is dependent on a number of factors, which include whether assessment data is being collected, how valid the data needs to be, and whether the portfolio is being used for formative assessment, summative assessment, or professional development and promotional purposes. When the portfolio is playing a crucial role in an assessment program it is recommended that an evaluation team is established to insure validity (Sweat-Guy \& Buzzetto-More, 2007).

Since rubrics have been identified as the ideal means for portfolio assessment (Buzzetto-More \& Alade, 2006) this will probably be the assessment regime adopted. Rubrics are known to help standardize assessment, provide useful data, and articulate goals and objectives to learners. Rubrics are also particularly useful in assessing complex and subjective skills (Dodge \& Pickette, 2001). During the rubric development process the rubric must be organized around the performance indicators established earlier in the adoption process.

\section{Level V: Implementation \& Growth}

During the fifth level, and final stage, of the portfolio adoption process the institution will need to pilot test the system, prepare student for implementation, engage in full implementation, and begin the cycle of continuous assessment and improvement.

\section{Preparing Students for Implementation}

Preparing students for implementation involves the development of the introduction/orientation mechanism. This requires the institution to consider when, and how, the portfolio will be introduced; whether the students will require training as well as where and how that training will that occur; and how and what resources will be made available to students.

\section{Pilot Test}

Pilot testing should begin with faculty training and usage followed by partial implementation with a small group of student users. The results of the pilot should be assessed and improvements should be made prior to full implementation.

\section{Full Implementation}

Full implementation should never be rushed. Only after all other considerations have been addressed, results for the pilot assessed and improvements made, and a contingency plan in place, should full implementation occur.

\section{Longitudnal Growth and Continuous Improvement}

As with any assessment program, adoption and usage of an electronic portfolio involves a process of longitudinal growth and continuous improvement. A successful program will grow and improve over time and be part of a cycle of continuous improvement.

\section{Senior Capstone E-Portfolio Project}

The University of Maryland Eastern Shore is a Historically Black University (HBU) established in 1886 and located within the United States. It is a public university and a member of the University system of the State of Maryland. The student population is approximately 4,000, represented by a student body that is currently $91 \%$ African-American. The freshmen retention rate is $62 \%$, and the graduation rate is $42.6 \%$. The Department of Business Management and Accounting (DBMA) is one of the largest departments on campus. The Department has approximately 420 
students, offering programs that include Business Administration, Accounting, Business Education, Finance, and Marketing.

Historically Black Colleges and Universities (HBCUs), while small in number, graduate the preponderance of African Americans who earn college degrees in America (Hubbard, 2006). While they constitute only 3 percent of U.S. colleges and universities, they enroll 28 percent of all African American college students and graduate 40 percent of the Black Americans who earn doctorates or first professional degrees (Hubbard, 2006).

Willie, Reddick, and Brown (2005) compared contemporary HBCUs to their counterparts from decades ago. They found that HBCUs a generation ago were dedicated to opening doors closed to students whose academic backgrounds reflect low achievement, by providing remedial, mentoring, and supportive services to students; the mission of contemporary HBCUs remains the same. They explained that the goal of opening new opportunities while rectifying deficits of the past and preparing students for professional and academic success remains at the fore. Further, they concluded that non-Blacks can often benefit from the unique kind of education offered by these institutions.

Concurrent with the mission of HBCUs to open doors for students by creating opportunities for students to succeed is the current growth in electronic portfolio usage at these institutions (Buzzetto-More, 2006), which is illustrated in the portfolio project described in this paper and influenced by the literature that explains that electronic portfolios offer numerous advantages over standardized tests and comprehensive exams for their flexibility and adaptability (BuzzettoMore, 2006; Cooper, 1999; Office of Educational Research and Improvement ,1993b; American Association of Higher Education, 2001).

Beginning in 2005, as part of an aggressive assurance of learning and continuous improvement effort, as well as in conjunction with an accreditation application and review from the American Association of Colleges and Schools of Business International (AACSB), an Assurance of Learning Committee was established in the University of Maryland Eastern Shore's (UMES) Department of Business, Management, and Accounting (DBMA). Assurance of Learning Committee members were doctoral degree holding tenured or tenure track faculty from within the Department of Business, Management, and Accounting who had existing knowledge and experience with curriculum development and student learning outcomes assessment. All members met the AACSB requirements for designation as Academically Qualified and had attended a variety of assessment workshops. The appointed committee chair was an acknowledged e-learning and assessment expert who was also designated with coordinating the assessment efforts of the Department. Members of this crucial committee were charged with the redevelopment of the student learning outcomes of the Department, the redesign of the assessment program, and finding a culminating assessment measure that complimented and best fit the academic and professional needs of students in compliment with the academic mission of the institution.

A number of comprehensive assessment options were examined including, but not limited to, a comprehensive exam, an assessment center, and an internship experience. Emerging from this investigation, and supported by the preponderance of the literature, was the recognition of the high success rates of electronic portfolios, which are shown to effectively provide an alternative and effective means of assessing student learning outcomes while having high acceptance rates among students (Buzzetto-More, 2006).

Additionally, the decision to adopt an electronic portfolio was heavily influenced by an electronic portfolio project that had been implemented by the University's Department of Education The electronic portfolio project successfully implemented in the education unit utilizes the TK20 system, in which all graduating teacher education degree candidates are required to create a portfolio designed around national, state, institutional, and professional standards. 
As a result of the findings, it was unanimously decided by the DBMA Assurance of Learning Committee that a senior capstone portfolio would provide the optimal form of purposeful and authentic assessment that best suited the needs of the diverse learners that the department serves.

\section{Level I: Identification of Need}

\section{Define Learning Outcomes}

A series of student learning goals/outcomes were established for both the Department as a whole as well as for each individual degree program within the Department. Furthermore, the learning outcomes of the Department were aligned with the learning goals of the larger University.

\section{Identify Performance Indicators}

Each learning outcome was expanded upon by measurable performance indicators that were written using the vernacular established in Bloom's Taxonomy of Educational Objectives. They were specifically created to serve as the demonstrable performance based actions that could be effectively measured (Walvoord \& Anderson, 1998).

\section{Determination of Purpose}

It was determined that the portfolio would serve initially as a form of mastery based assessment where all graduating seniors would be required to complete a capstone portfolio prior to graduation. It was also decided that, if successful, at a later date the portfolio project would be expanded to a form of comprehensive assessment where students would be engaged in the development process throughout their time in the academic degree program culminating in the graduating semester.

It was decided that students would have control of authorship and ownership; however, for quality assurance the portfolio creation and evaluation process would have guidelines. Additionally, it was agreed that the portfolios should be organized around the Department's learning goals.

\section{Level II: Determination, Assessment, \& Budgeting}

\section{Selection of Features}

Features were selected, and, because the institution already possessed a sophisticated course management system and an online survey tool, as well as an advisement system, it was decided, using the matrix created by Sweat-Guy and Buzzetto-More (2007), that desired platform features included the support of a wide variety of artifact formats, communication capabilities, self hosting, learning outcome creation and linkage, reflection creation, and linkage to the existing course management system.

\section{Assessment of Existing Technology Infrastructure}

The technology infrastructure was assessed, and it was decided that the system could be hosted by the institution, allowing for localized control and greater scalability. Server space was identified as being available, and it was agreed that technological support would be established through both the University's Office of Instructional Technology as well as more locally within the Department through the appointment of a portfolio coordinator well trained in usage of the system. 


\section{Determination of Portfolio Type}

The department decided that it was not interested in creating a completely new homegrown portfolio system as this would be too burdensome, too time consuming, and cost prohibitive. It was also determined that a portfolio using simple off-the-shelf software would not be adequate as the portfolios would be overly simplistic. As a result, the Department decided on either a commercially available or open source system.

\section{Budget Formation}

A modest budget was developed that would accommodate the purchase, installation, development, and hosting of a portfolio. It was determined that the University's Office of Instructional Technology would be responsible for administration. It was also decided that no costs would be passed on to students; as a result, limited funding was available for dedicated personnel making the local Business Department level portfolio project coordinator(s) volunteers.

\section{Level III: System Selection \& Strategic Planning}

\section{System Selection}

Based on the findings of the comparisons aligned with the features and needs previously determined, the Assurance of Learning Committee decided to examine commercially available portfolio platforms as well as the largest open source portfolio system. A matrix was developed based on the work of Sweat-Guy and Buzzetto-More (2007) and used to conduct a side by side comparison of the eight most popular platforms, which included Foliotek, TK20, TaskStream, Eportfolio, Live Text, True Outcomes, the Open Source Portfolio Initiative, and the Blackboard Portfolio product (then only available in pre-release). Based on the examination it was decided that the Blackboard Portfolio product best fit the needs of the project. This product was particularly desirable because the Blackboard Electronic Portfolio System is designed to compliment, and be used in conjunction with, the Blackboard Vista and CE learning management systems employing a similar interface and functionality. Furthermore, it satisfied all needs by allowing students to present a collection of items that represent their accomplishments towards the satisfaction of student learning outcomes as well as enabling students to share their portfolio(s) with internal and external assessors, instructors, friends, and individuals outside of the institutional community, such as potential employers.

Students who use the system are able to create multiple portfolios using multiple artifacts linked to institutional and/or personal learning goals. Students can alter their portfolios for different viewers, invite and dis-invite assessors and guests internal and external to the institution, and allow people to give feedback. Students can also create and refine learning goals as well as author public and private reflections, discussions, and blogs. Additionally, graded material from online courses can be imported directly into portfolios.

During the summer of 2006, the Blackboard portfolio product, in agreement with the Blackboard company, was tested and used as part of a pre-pilot examination and preparation process with a group of faculty at UMES in partnership with the assistance of the UMES Office of Instructional Technology. This experience enabled some preliminary training, structuring, resource generation, and guideline formation. 


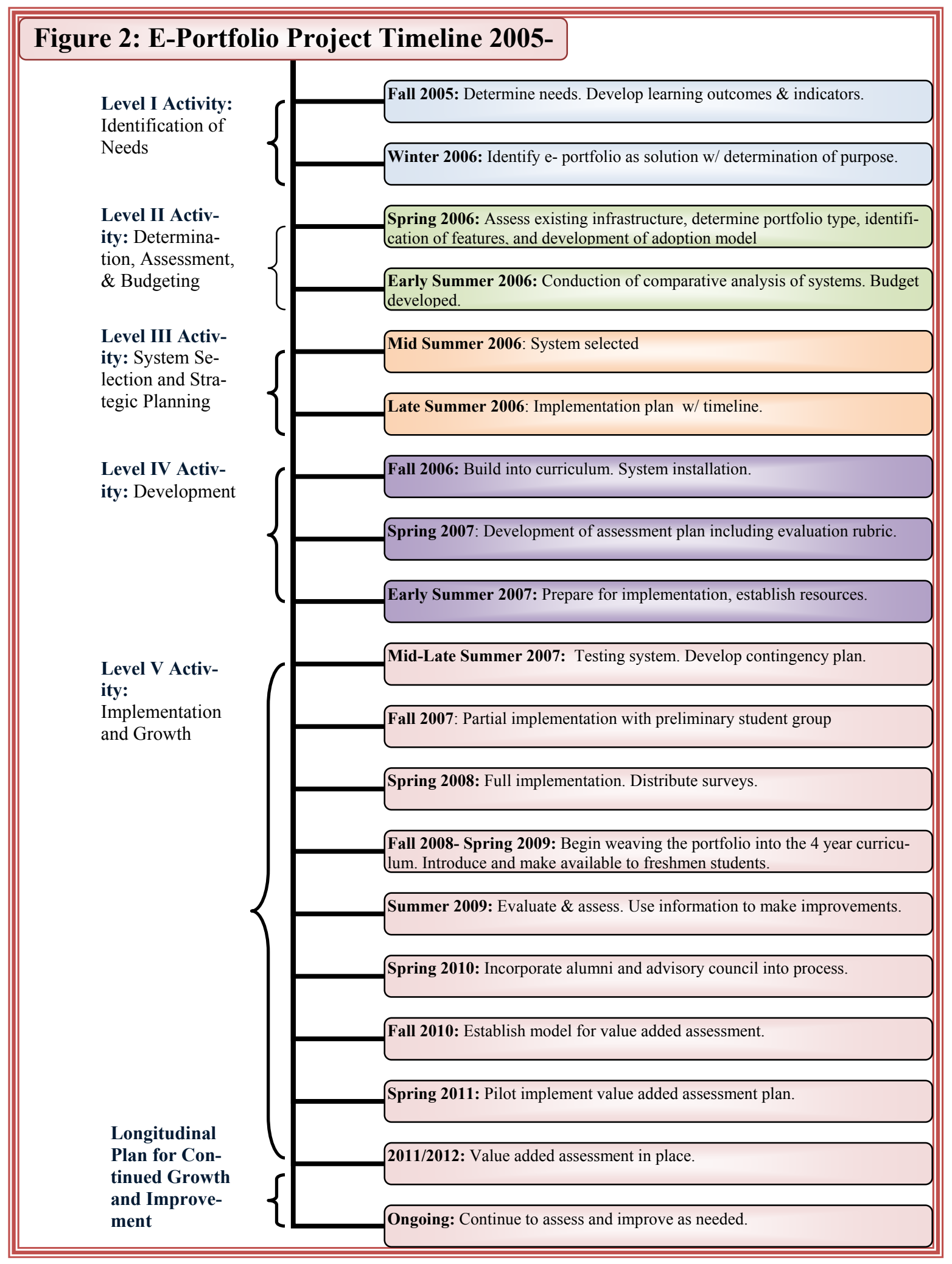

Figure 2: E-Portfolio Project Timeline 2005 - 


\section{Development of Strategic Implementation Plan}

Once the system was selected and preliminary testing occurred, it was time to develop a realistic and detailed implementation plan that included a feasible timeline. Figure 2 represents the timeline and aligns all activities with the levels of the Pentagonal E-Portfolio Model.

\section{Level IV: Development}

\section{Establishment of All Resources}

With the implementation plan in place, resources were established which included the development of user manuals for both students and faculty, the creation of a custom guide for student portfolio creation, the location and acquiring of technological resources to assist students in portfolio generation, the securing of training and technical support for students and faculty, and the development of a portfolio implementation and assessment team.

\section{Build Portfolio into Curriculum}

When building the portfolio into the curriculum, it was decided that a course embedded methodology was preferred. The course that best suited the needs of the project was BUAD 495: Strategic Management, which serves as the department's capstone course.

Capstone courses are generally offered by an academic institution to serve as a culminating experience, and they are usually taken by students during their final semester prior to graduating. Capstone courses are commonly project intensive and involve a variety of activities that require students to employ much of the knowledge, skills, and dispositions that have developed throughout their time in a particular academic degree program. Capstone courses help to draw linkages between concepts while solidifying a student's understanding of real world applications.

The capstone course for the Department of Business, Management, and Accounting prior to the integration of the e-portfolio included a range of activities, the most prominent being a comprehensive competitive web-based simulation involving the application of core business concepts; critical thinking, decision making, and problem solving applied to interactive real world scenarios; process diaries; both peer and self evaluations; individual and group work; and exogenesis. It was decided by the Assurance of Learning Committee that the simulation activity should remain significant within the capstone experience, with the e-portfolio taking center stage.

While incorporating the electronic portfolio project into the department's capstone course, it was embedded within the course in so much that for the pilot semester it played only a marginal portion of the term grade. This was done to minimize the stress placed on students. It was also decided that, as implementation continued, the weight of the portfolio into the students' term grades would become increasingly more significant. The concern arose that students might decide not to complete the portfolio. As a result, it was agreed that once fully implemented, completion of the portfolio would be a requisite activity.

Concurrent with the activities that took place to embed the student portfolios within the capstone course, there was also the need to align this activity with the larger curriculum and existing assessment measures. As a result, the e-portfolio was aligned with the university's general education competency areas, departmental learning goals, and existing assessment, measures. This alignment served multiple purposes. First, it helped to illustrate how the electronic portfolio fit into the overall learning experience of students. Secondly, it provided inspiration to students to help them recognize activities that they were engaged in during their academic career that may have generated valuable artifacts that could be included within their electronic portfolio. Figure 3 represents this alignment. 


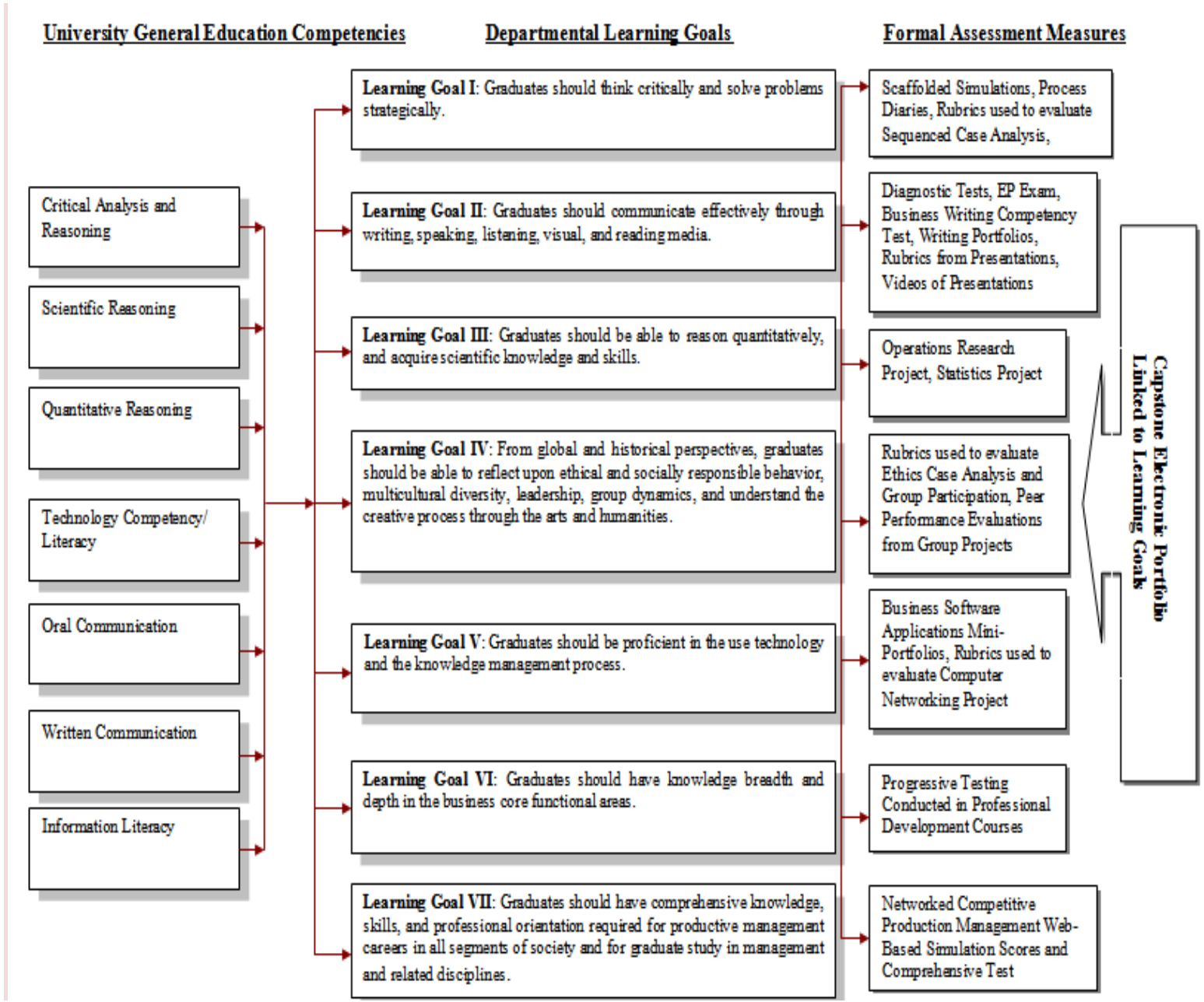

Figure 3: Alignment of Learning Goals with Assessments \& Electronic Portfolio Experience

\section{Rubric Development}

A rubric was developed (see Table 3 ) for assessing student portfolios. The rubric was created around the DBMA learning goals, applying a four point criteria scale represented as target (10 points), acceptable ( 7.5 points), developmental ( 5 points), and unacceptable/missing ( 0 points). The performance indicators were embedded within the evaluation criteria and a requisite score of 60 points was set as a minimally acceptable score, whereas students earning below the 60 point cut off were required to rework and resubmit their portfolios. Overall, the rubric was designed to be comprehensive in order to ease the evaluators' assessment, provide meaningful feedback to learners, and to generate useful data that can be aggregated/ disaggregated and analyzed for reporting and decision making. Who would be using the rubric emerged as a critical question. It was decided by the Assurance of Learning Committee that an evaluation team would be created to employ the rubric and engage in the evaluation. The usage of evaluation teams is a common practice with electronic portfolios as a means to insure reliability and validity (Buzzetto-More, 2006). Evaluation teams commonly consist of multiple stakeholders, such as instructors, program coordinators, administrators, industry professionals, alumni, and/or advisory board members. The size of evaluation teams varies, although they usually have three or more members. 


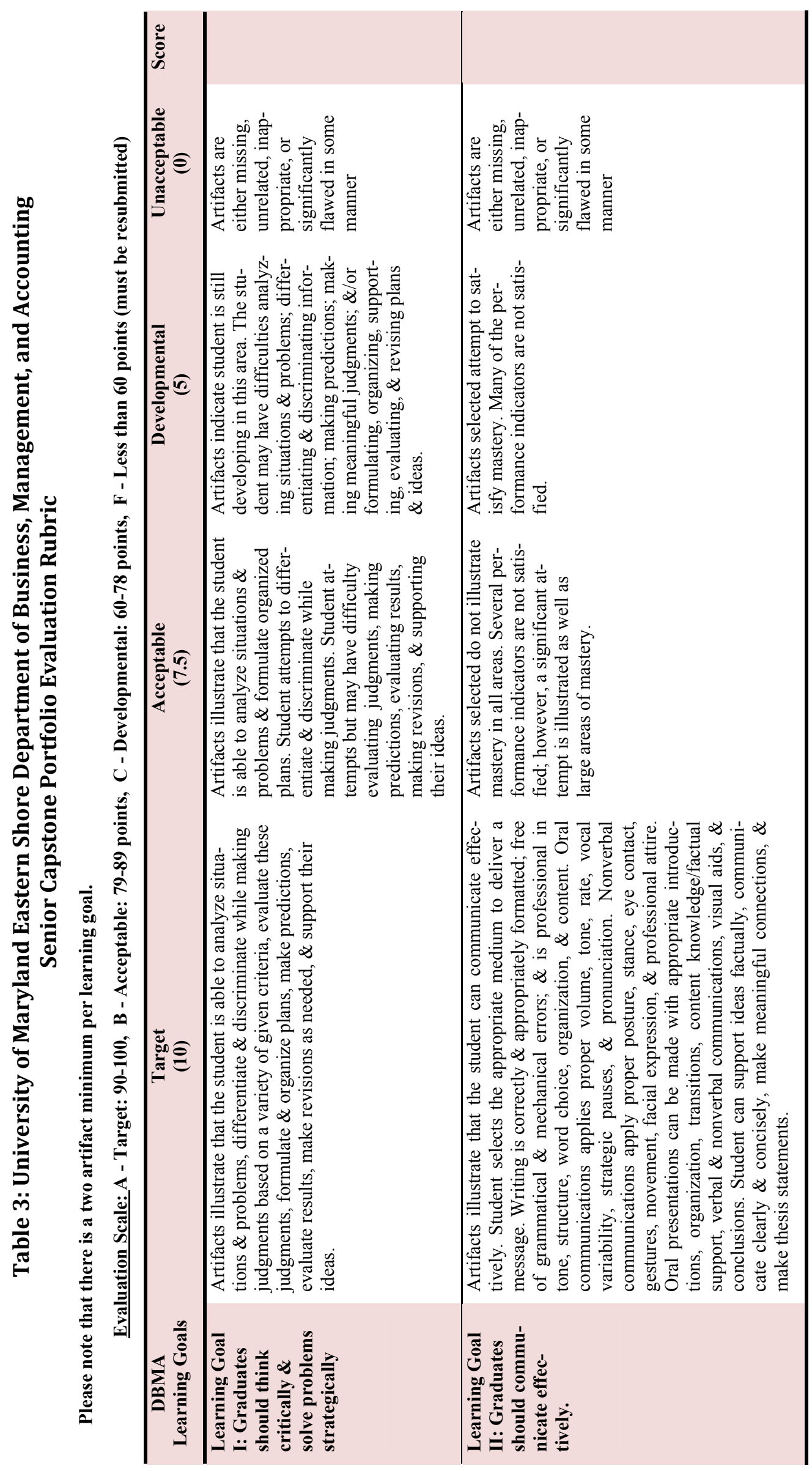




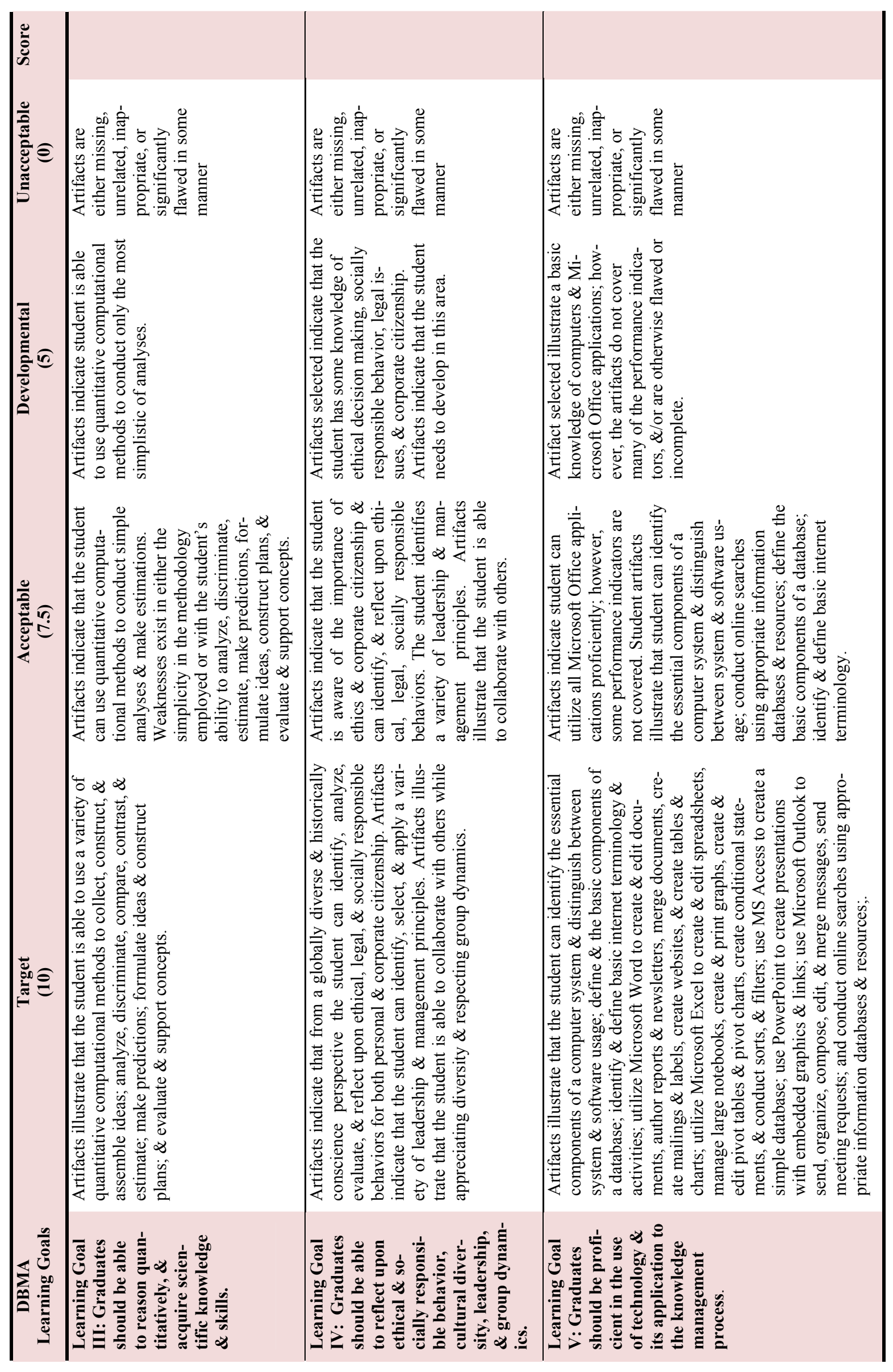




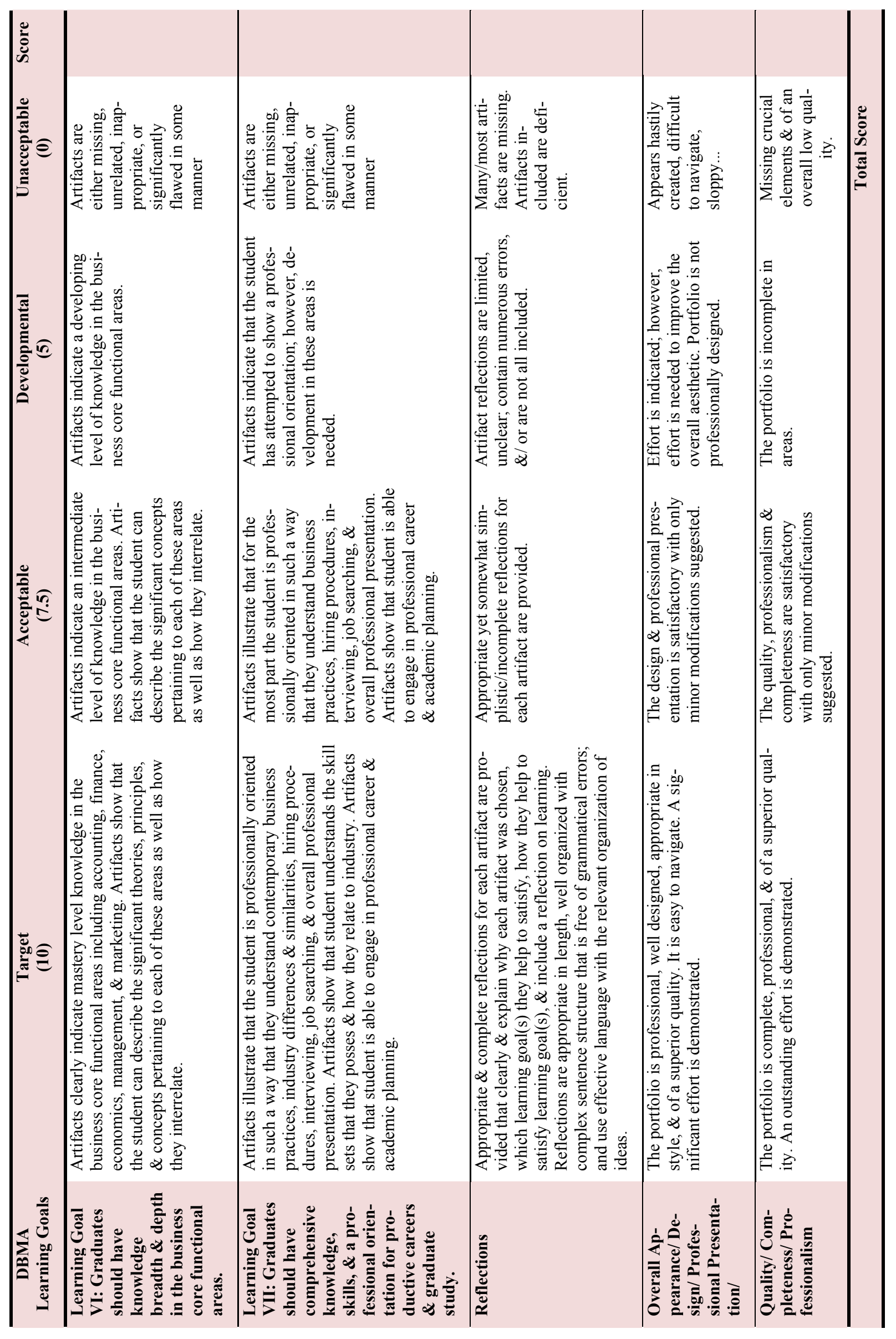




\section{Level V: Implementation \& Growth}

\section{Preparing Students for Implementation}

Because it was determined that student preparation was vital to the success of this project, a number of activities and resources were designed. This process required the portfolio committee to consider how to introduce the portfolio to students, how the concepts should be presented, how training should be structured, and the optimal sequencing of these activities. This all had to be established prior to the initial student pilot.

\section{Pilot Test}

The student pilot occurred during the fall semester of 2007 with a group of 30 students scheduled to graduate in December of 2007. Participating students were first introduced to and provided with preliminary information about the portfolio project within the course syllabus by the instructor the first day of class. Students had been pre-enrolled in their individual portfolios prior to the start of the term and were encouraged to engage in an initial exploration of the system as early as possible. During the second week of the semester, the Department level portfolio coordinator was welcomed by the instructor to visit with the students going over the student portfolio creation guide/user manual as well as providing examples, discussing assessment, answering questions, and engendering discussion. The creation guide/user manual, which was custom created for use by the Department, explained the pedagogy behind the capstone portfolio project; defined major concepts and terms; articulated the benefits to the students of outcomes based portfolios for academic, personal, and professional usage; explained the department's learning goals and coordinating performance indicators; provided guidance for artifact selection; described the meanings and importance of artifacts; explained the importance of reflections as well offered guidelines for reflection generation; articulated the evaluation process; and presented the evaluation rubric. The user manual portion provided illustrated step by step directions for usage of the system as well as useful tips and suggestions. It was designed to be organized purposefully and user friendly. Figure 4 is a snapshot taken from the actual illustrated directions provided to students.

It was planned that during the third week of the semester the student would be taken to the Office of Instructional Technology where, in a lab environment, usage of the system would be discussed and training provided. Additionally, students would be familiarized with the resources and technical support available to them through this institutional resource. Unfortunately, due to cancellations and a lack of rescheduling this event did not occur.

The portfolios created and responses generated by the initial student user group yielded positive results. Minor modifications were made prior to full implementation and the Assurance of Learning Committee solidified several decisions. The modifications made included:

- an expansion of the performance indicators described in the rubric,

- additions to the student guide/user manual, and

- the establishment of dedicated times in which the students could come work on the portfolios in a reserved, established, and fully supported environment.

Additionally, at this time, the Assurance of Learning Committee determined that the project timeline and coordinating activities would continue to commence as envisioned. 


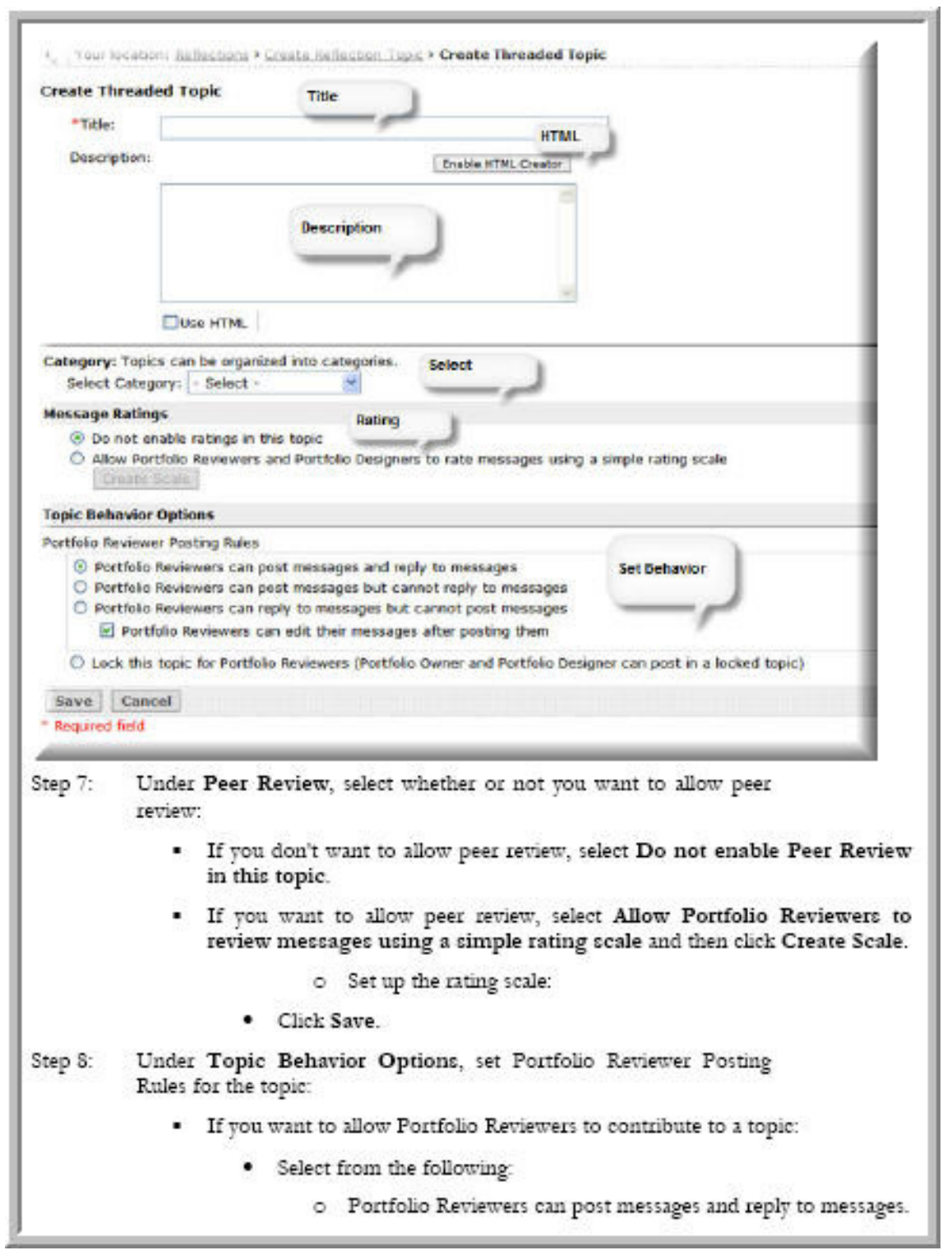

Figure 4: Sample Illustrated Student Directions

\section{Full Implementation}

The senior capstone electronic portfolio project was fully implemented in the spring semester of 2008 and the project continues to move forward. Also in the spring of 2008 an electronic portfolio utilizing the same Blackboard Portfolio System being used in the senior capstone project was implemented in BUAD 213: Business Software Applications, an intermediate level computing course required of all students majoring in business. In the fall of 2008, the portfolio was further integrated throughout the departmental curricula, with full integration in BUAD 213 and piloting in BUAD 300: Business Ethics. Perhaps most significantly, the portfolio was introduced to freshmen students who will have access to their portfolios throughout their academic experience. These activities will enable the portfolio building process to begin earlier during the academic program and allow for the scheduling of periodic progress reviews that can be used to consult learners as well as serve as value added assessment. 
It was also decided that students will retain access to, as well as ownership of, their portfolios for a period of ten years following their graduation from the institution. This was considered important for several reasons. First, it serves as another mechanism for accessing and contacting alumni. Second, it serves as a tool that can be used by students to assist in graduate school admissions. Third, it can be used by students for professional promotion. Fourth, when it continues to be developed and utilized by students, it can serve as a means of value added assessment that illustrates the continued growth and development of the student.

\section{Longitudinal Growth and Continuous Improvement}

As with any assessment program, adoption and usage of an electronic portfolio involves a process of longitudinal growth and continuous improvement. When making such a significant addition to the academic experience, it is important to conduct an evaluation. The Department decided to asses both student portfolio performances as well as evaluate student satisfaction with the portfolio. As a result, a student satisfaction survey was created to gather the perceptions and opinions of students as part of a commitment to continuous improvement. The survey was designed to examine student perceptions of the professional and academic usefulness of the portfolio; technology used to create the portfolio; support and guidance offered; resources and materials; the experience with the portfolio creation process; whether the portfolio helped them identify the knowledge, skills, and dispositions developed during their time in the Department; success of the portfolio in helping them reflect upon the total learning experience; and whether the portfolio was useful in

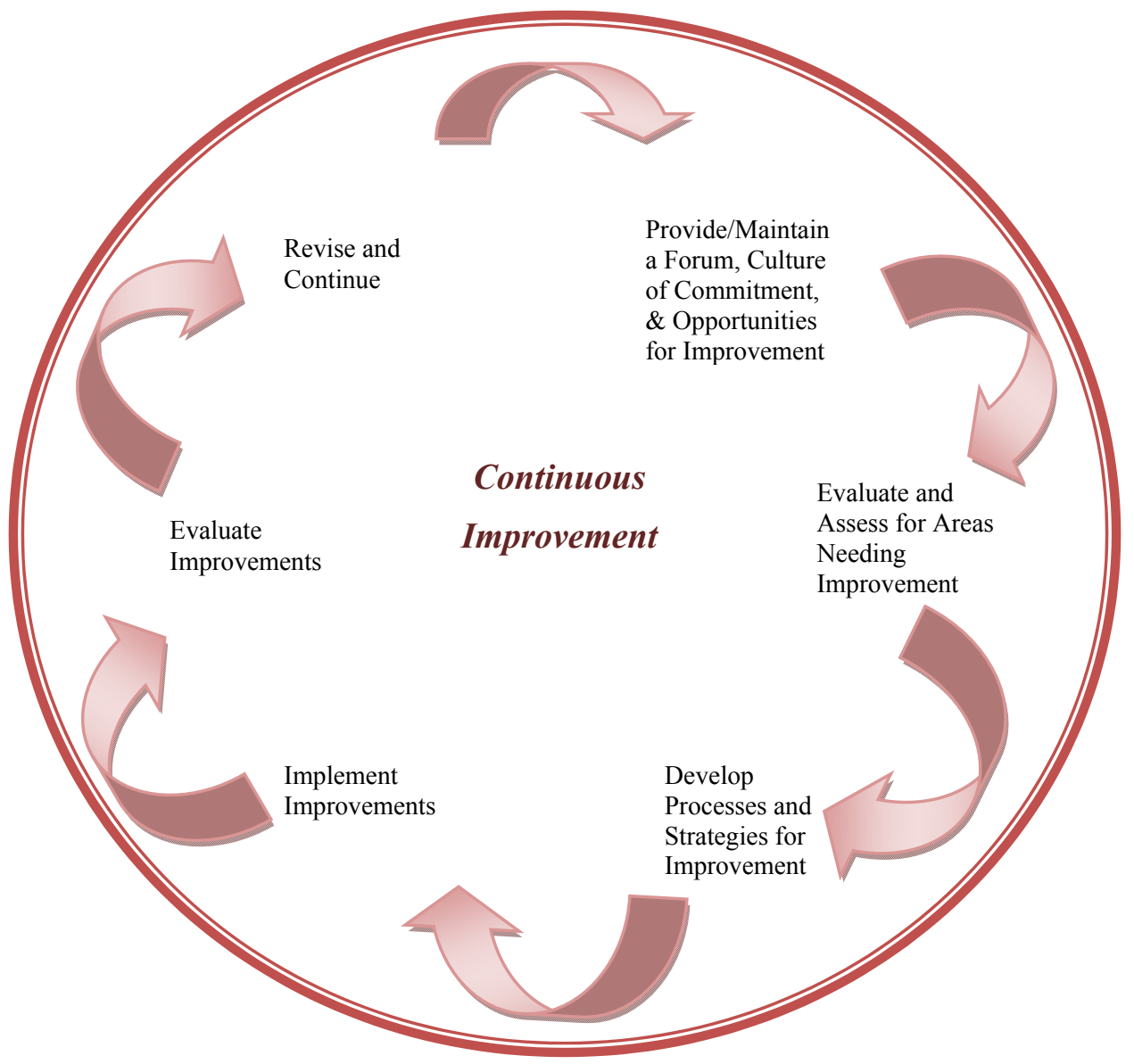

Figure 5: Continuous Improvement Model 
helping them better understand the linkage between academic concepts and real world business practices. Student survey data is being collected along with evaluation rubrics. This data will undergo a detailed assessment during the summer of 2009. The results of these findings will assist the portfolio team in the improvement of the project.

A continuous improvement model (see Figure 5) has been developed and is being employed to ensure purposeful longitudinal growth and continuous improvement within an academic culture committed to assurance of learning and student learning outcomes assessment.

\section{Summary and Future Work}

There are many tools and strategies that can be used in the development of an electronic portfolio project. After a thorough review of the literature, discussions with other colleagues, and the development of a student learning outcomes electronic portfolio project, the authors have presented a practical model for adopting an electronic portfolio known as the Pentagonal E-Portfolio Model based on five levels that include the following: 1) Level 1 - Identification of Needs; 2) Level 2 Determination, Assessment, \& Budgeting; 3) Level 3 - System Selection and Strategic Planning; 4) Level 4 - Development; and 5) Level 5 - Implementation and Continuation.

This paper has illustrated the practical application of the Pentagonal E-Portfolio Model by providing a detailed case study of one successful and ongoing portfolio project used as a comprehensive assessment measure to determine degree mastery in an undergraduate business program currently undergoing accreditation with the American Association of Colleges and Schools of Business International.

While the authors assert that a robust electronic portfolio decision making and adoption model has been offered in this paper, as with any newly developed conceptual enterprise, there are limitations that were not unearthed until the model had been fully employed and tested. The Pentagonal Electronic Portfolio Model presented covers all major activities thoroughly with the exception of one activity that perhaps should have been included within the first activity level of the model. The neglected activity is portfolio/assessment committee formation, in particular committee member selection. Seeing as the committee will ultimately be responsible for the decision making regarding adoption and implementation, the selection and/or appointment of members is important. The authors suggest that committee members are selected strategically. Whenever possible, individuals with prior knowledge and experience of student learning outcomes assessment as well as genuine interest in alternative assessment, project based learning, e-learning, and/or electronic portfolios should be selected. Paramount to committee membership is commitment

This paper has been purposed to assist educators in the understanding, discovery, decision making, adoption, preparation, implementation, and evaluation of electronic portfolios. The authors hope that this paper helps to make a small contribution to the literature, discourse, and growth of electronic portfolios as authentic student learning outcomes oriented assessment instruments. 


\section{References}

American Association for Higher Education. (2001). Electronic portfolios: Emerging practices for students, faculty and institutions. Retrieved 11/21/2007 from

http://aahe.ital.utexas.edu/electronicportfolios/index.html

Batson, T. (2005). The current state of electronic portfolios in higher education. EDUCAUSE Connect. Retrieved 11/21/2007 from http://connect.educause.edu/Library/Abstract/TheCurrentStateofEPortfol/41357

Butler, P. (2006, October). A review of the literature on portfolios and electronic portfolios. Retrieved 11/21/2007 from https://eduforge.org/docman/view.php/176/1111/eportfolio $\% 20$ Project $\% 20$ Research $\% 20$ Report.pdf

Buzzetto-More, N. (2006). Using electronic portfolios to build information literacy. Global Digital Business Review, 1(1), 6-11.

Buzzetto-More, N., \& Alade, A. (2006). Best practices in e-assessment. Journal of Information Technology Education, 5, 251-269. Retrieved from http://jite.org/documents/Vol5/v5p251-269Buzzetto152.pdf

Chun, M. (2002). Looking where the light is better: A review of the literature on assessing higher education quality. Peer Review, Winter/Spring, 16-25.

Cooper, T. (1999). Portfolio assessment: A guide for lecturers, teachers and course designers. Perth: Praxis Education.

Cooper, T., \& Love, T. (2002). Online portfolios: Issues of assessment and pedagogy. In P. Jeffrey (Ed.), AARE 2001: Crossing borders: New frontiers of educational research (pp. 417-426). Coldstream, Victoria: AARE Inc.

Dodge, B., \& Pickette, N. (2001). Rubrics for Web lessons. Retrieved 12/10/2008 from http://edweb.sdsu.edu/webquest/rubrics/weblessons.htm

ePortConsortium.Org. (2003). Electronic Portfolio White Paper [Version 1.0]. Retrieved 10/2/2006 from http://eportconsortium.org

Harich, K., Fraser, L., \& Norby, J. (2005). Taking the time to do it right. In K. Martell \& T. Calderon (Eds), Assessment of student learning in business schools: Best practices each step of the way, 1(2), 119-137. Tallahassee, Florida: Association for Institutional Research.

Hubbard, D. (2006). The color of our classroom, the color of our future. Academe, 92(6), 27-29.

Jafari, A. (2004). The sticky e-portfolio system: Tackling challenges and identifying attributes. Educause Review, 39(4), 38-49.

Love, T., \& Cooper, T. (2007). Electronic portfolios in e-learning. In N. Buzzetto-More, Advanced principles of e-learning (pp. 267-292). Santa Rosa, CA: Informing Science Press.

Lorenzo, G. \& Ittelson, J. (2005a). An overview of electronic portfolios. EduCause Learning Initiative. ELI Paper 1: 2005. Retrieved 8/9/2006 from http://net.educause.edu/ir/library/pdf/ELI3001.pdf

Lorenzo, G, \& Ittelson, J. (2005b). Demonstrating and assessing student learning with electronic portfolios. EduCause Learning Initiative. ELI Paper 3: 2005. Retrieved 8/9/2006 from http://net.educause.edu/ir/library/pdf/ELI3003.pdf

Martell, K., \& Calderon, T. (2005). Assessment of student learning in business schools: What it is, where we are, and where we need to go next. In K. Martell \& T. Calderon (Eds), Assessment of student learning in business schools: Best practices each step of the way, 1(1), 1-22. Tallahassee, Florida: Association for Institutional Research.

Office of Research Education (OERI). (1993a). Consumer guide: Performance assessment. Retrieved 9/1/2007 from http://www.ed.gov/OR/ConsumerGuides/perfasse 
Office of Research Education (OERI). (1993b). Consumer guide: Student portfolios: Classroom uses. Retrieved 9/1/2007 from http://www.ed.gov/OR/ConsumerGuides/classuse.html

Sweat-Guy, R., \& Buzzetto-More, N. (2007). A comparative analysis of common e-portfolio platforms and available features. Issues in Informing Science and Information Technology Education, 5(1). 327-342. Retrieved from http://proceedings.informingscience.org/InSITE2007/IISITv4p327-342Guy255.pdf

Walvoord, B. E., \& Anderson, V. J. (1998). Effective grading: A tool for learning and assessment. San Francisco: Jossey-Bass.

Willie, C. V., Reddick, R. J., \& Brown, R. (2005). The black college mystique. Lanham, MD: Rowman \& Littlefield.

Zeichner, K., \& Wray, S. (2001). The teaching portfolio in US teacher education programs: What we know and what we need to know. Teaching and Teacher Education, 17(5), 613-621.

\section{Biographies}

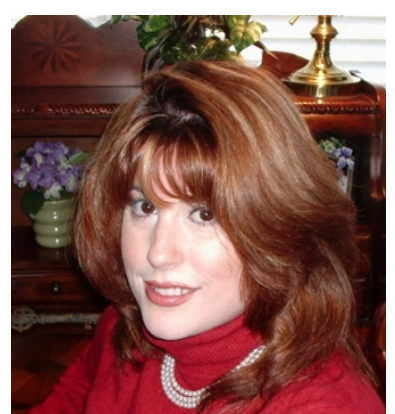

Dr. Nicole A. Buzzetto-More is an Associate Professor, Business Education program coordinator, and Assurance of Learning coordinator in the Department of Business, Management, and Accounting at the University of Maryland Eastern Shore. She is also Co-Founder of the UMES Office of Instructional Technology. She received doctorate and masters degrees in communication and instructional technology from Columbia University and also holds degrees from the College of New Rochelle and Marist College. As a recognized assessment and elearning expert, she is a frequent presenter at conferences across the globe. She is on the editorial board of several journals, has authored numerous publications in referred journals, and has been recognized with awards from the American Distance Education Consortium, Global Digital Business Association, and the Informing Science Institute. Her two books published in early 2007, Principles of Effective Online Teaching and Advanced Principles of Effective E-Learning, are available through the Informing Science Press. She is currently working on book chapters for two different books to be published in late 2008 and a book dedicated to e-portfolios to be published by the Informing Science Press in 2010 .

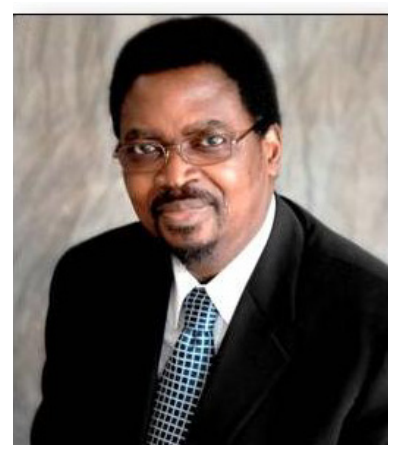

Dr. Ayodele Julius Alade is dean of the School of Business and Technology at the University of Maryland Eastern Shore. Originally from Nigeria, he has degrees from Cuttington University in Liberia and the University of Utah. His areas of specialization include: operations management, quantitative methods, international and developmental economics, industrial economics, and corporate finance. He has over 60 referred publications, made numerous presentations, and continues to hold a number of large-scale grants all of which are either interdisciplinary and/or international in scope. He has been involved and conducted a number of international assignments sponsored by USAID and has received several honors and awards for this work. He also has extensive experience in program development and professional program accreditation. 